\title{
Physical Examination in Medicine
}

\section{Alfonso Lagi MD*}

Villa Donatello Hospital, Florence, Italy

Everything we see hides another thing, we always want to see what is hidden by what we see. There is an interest in that which is hidden and which the visible does not show us.

\section{René Magritte}

The target of physical examination is to reach a successful diagnosis, as other tools already do such as anamnesis and clinical instrumental examinations.

The most appreciated trait of physical examination is to be affordable. So it is believed, although it is not entirely true.

It must be said that in order to obtain a reliable physical examination it must be carried out by trained and skilled professional clinicians. Therefore a physical examination becomes a performance comparable to diagnostic investigations at average cost, certainly more expensive than the cost of a standard X-ray or ultrasound examination.

Physical examination provides many diagnoses with certainty and contrary to what you might believe, it should not be considered only to complete or avoid specific exams able to confirm the diagnosis $[1,2]$.

The misunderstanding can be solved if you think that there are various levels of clinical diagnosis.

For instance noticing that the patient has a higher than normal body temperature and detect tachycardia and tachypnea is enough evidence to put the fever diagnosis with a high approximation. It explains the expression 'Woe to the doctor who thermometer needs to know if your patient has fever'.

Detecting that a patient has fever does it mean we just made a diagnosis? It certainly does. This is a symptomatic diagnosis, i.e. you diagnose the presence of a symptom. It is true that the doctor and the patient seek to have a disease-causing diagnosis too. At this regard physical examination alone requires also an epidemiological context. Think of the number of fever diagnosis during an influenza epidemic. The etiological diagnosis is made.

It's even better if you combine physical examination with the medical history. It's hard not to diagnose pneumonia when you detect symptoms such as wet crackles at a lung associated with inspiratory pain, fever and reddish sputum. context.
Like any other diagnostic test, physical examination is prone to uncovering incidental findings and false-positives that might become confounding [3]. It would emphasize selective application of the physical examination in appropriate clinical contexts, recognizing that highly specific findings in a low-risk population are likely falsepositives or vice versa.

Although clinicians strive to emphasize the importance of physical examination it is not broadly practiced, and still less taught. It is certainly easier to rely on effective diagnostic methods that are less time consuming for the prescriber and will allow you to use a provably data like imaging or blood chemistry one. The scientific community should investigate and prospectively validate more diagnostic algorithms or scoring systems that incorporate known high-yield physical findings with other diagnostic tests.

On the other hand patients seem to prefer more a diagnosis based on provable data compared with the subjectivity of the data reported by your practitioner [4-6].

Finally what not least, physical examination allows you to create an empathetic relationship with the patient. This should not be underestimated in the process of continuity of care.

\section{References}

1. Bergel P, Farnan JM, Chan E (2015) Moving Toward Cost-effectiveness in Physical Examination. The American Journal of Medicine 128: 109 - 110.

2. American College of Cardiology Foundation Appropriate Use Criteria Task Force, American Society of Echocardiography, American Heart Association, American Society of Nuclear Cardiology, Heart Failure Society of America, Heart Rhythm Society et al. ACCF/ASE/AHA/ASNC/HFSA/HRS/SCAI/SCCM/ SCCT/SCMR 2011 appropriate use criteria for echocardiography. J Am Soc Echocardiogr. 24: 229-2

3. Rothberg MB (2014) A piece of my mind. The $\$ 50,000$ physical. JAMA 311 : 2175-2176.

4. Verghese $\mathrm{A}(2008)$ Culture shock-patient as icon, icon as patient. N Engl J Med 359: 2748- 2751.

5. Elder A, Chi J, Ozdalga E, Kugler J, Verghese A (2013) A piece of my mind: the road back to the bedside. JAMA 310: 799-800.

6. McGee S. Evidence-Based Physical Diagnosis. 3rdedtn. Elsevier Saunders Philadelphia, PA; 2012 In: D.L. Simel, D. Rennie, S.A. Keitz (Eds.) The Rational Clinical Examination: EvidenceBased Clinical Diagnosis. McGraw-Hill Companies, New York; 2008
*Corresponding author: Alfonso Lagi, Florence, Italy, Tel: +39055583182; E-mail: alfonso.lagi1@tin.it

Received March 26, 2015; Accepted April 09, 2015; Published April 15, 2015

Citation: Alfonso Lagi MD (2015) Physical Examination in Medicine. Pigmentary Disorders 2: e106. doi:10.4172/2376-0427.1000e106

Copyright: ( 2015 Alfonso Lagi MD. This is an open-access article distributed under the terms of the Creative Commons Attribution License, which permits unrestricted use, distribution, and reproduction in any medium, provided the original author and source are credited. 